\title{
Frequent Hangovers and Cardiovascular Mortality in Middle-Aged Men
}

\author{
Jussi Kauhanen, ${ }^{1}$ George A. Kaplan, ${ }^{2}$ Debbie D. Goldberg, ${ }^{2}$ Richard D. Cohen, ${ }^{2}$ \\ Timo A. Lakka, ${ }^{1}$ and Jukka T. Salonen ${ }^{1}$
}

We studied the relation between frequent hangovers and cardiovascular mortality in a representative population sample of middle-aged Finnish men who participated in the Kuopio Ischemic Heart Disease Risk Factor Study. Complete data on alcohol consumption, hangover frequency, prior cardiovascular diseases, and risk factors were obtained for 2,160 non-abstinent men. Frequent hangovers were rare in the three lowest alcohol consumption quartiles, but in the highest quartile, a total of 239 men $(43.6 \%)$ reported having a hangover ar least monthly. During an average follow-up time of 6.7 years, these men had a 2.36 -fold ( $95 \%$ confidence interval $=1.02-5.48$ ) risk of cardiovascular death compared with men with fewer hang- overs, with adjustment for age and total alcohol consumption. The association was somewhat atrenuated after adjustments for smoking, income, and prior cardiovascular diseases. Systolic blood pressure, body mass index, resting heart rate, or serum lipids had no appreciable role in the relation, but plasma fibrinogen concentration appeared as one possible pathway to increased risk of cardiovascular death in men who frequently experience hangovers. The findings underline the importance of preventive actions regarding not only the amount but also the way people consume alcohol. (Epidemiology 1997;8:310314)

Keywords: alcohol, cardiovascular diseases, hangover, men, mortality, population studies, cohort study.

Higher rates of cardiovascular mortality have been observed in both heavy drinkers and nondrinkers as compared with light or moderate drinkers. ${ }^{1-8}$ Most population studies, however, have focused on the average amount of alcohol use. ${ }^{8}$ Although it is obvious that average alcohol intake does not sufficiently describe the variability in drinking patterns, few epidemiologic studies on cardiovascular morbidity and mortality $y^{9,10}$ have addressed this issue.

Heavy average drinking level is associated with several cardiovascular diseases and conditions, such-as hypertension, ${ }^{11-13}$ increased risk of hemorrhagic cerebrovascular disease, ${ }^{14}$ cardiac arrhythmias, ${ }^{15}$ and cardiomyopathy. ${ }^{16}$ The risk of coronary heart disease is also increased among heavy drinkers. ${ }^{17-19}$ Retrospective studies $^{20,21}$ have indicated underdiagnosis of alcohol

From the ${ }^{1}$ Research Insticure of Public Health and the Department of Communiry Health and General Practice, University of Kuopio, Kuopio, Finland, and ${ }^{2}$ Human Population Laboratory, Califomia Department of Health Services, Berkeley, CA.

Address correspondence to: Jussi Kauhanen, Deparment of Communiry Health and General Practice, University of Kuopio, P.O. Box 1627, 70211 Kuopio, Finland.

This research was supported in part by the Alcoholic Beverage Medical Research Foundarion, and by grants from the National Heart, Lung, and Blood Instirure (HL44199) and the Academy of Finland. Additional support was provided by the Yrjö Jahnsson Foundation, Finland.

Submitted April 8, 1996; final version accepred January 20, 1997.

C 1997 by Epidemiology Resources Inc. abuse in a large proportion of unexpected cardiovascular deaths.

Acure or recent intoxication may promote arrhythmia and ischemia. ${ }^{15}$ In turn, cumulative long-term effects of heavy acute intoxications are less well known except for increased blood pressure among persons with great variation in alcohol consumption. ${ }^{.1}$

The consumption of ethanol per capita in Finland represents the average level among Western European countries and the United States. ${ }^{22}$ The common drinking style in Finland has traditionally been fairly infrequent but acutely heavy consumption, which leads to drunkenness and acute withdrawal symptoms (hangover). ${ }^{23}$ Hangover represents a state of physiologic and metabolic stress in the body.

The present study prospectively investigated the relation between frequent hangovers and risk of cardiovascular death in middle-aged men. The adjustment for total alcohol consumption made it possible to go beyond the average drinking level and examine the independent effect of hangovers on cardiovascular death.

\section{Methods}

Subjects

The present study is part of the population-based Kuopio Ischemic Heart Disease Risk Factor Study (KIHD). The KIHD study was launched to investigate previously unestablished but promising risk factors for ischemic heart disease, extracoronary atherosclerosis, mortality, and related outcomes among middle-aged men. ${ }^{24}$ 
The study population is a stratified random sample of middle-aged noninstitutionalized men who were living in the town of Kuopio or neighboring rural communities at the time of the study baseline. The sample was stratified according to age; the men were age $42,48,54$, or 60 years at the baseline examinations, which were carried out between March 1984 and December 1989. Of 3,235 eligible men, $2,682(83 \%)$ participated.

We excluded men who reported no alcohol use during the past year ( $N=366$ ) from the present analyses. Complete information on total average alcohol use, frequency of hangovers, health status, history of smoking, and outcome was available for 2,160 of the 2,316 drinking men $(93.3 \%)$.

\section{Use of Alcohol And Hangovers}

Total alcohol consumption was assessed at the baseline with a structured quantity-frequency method using the Nordic Alcohol Consumption Inventory. ${ }^{25.26}$ Usual frequency and dose were reported separately for each beverage type. Total alcohol use was computed as the average weekly consumption in pure ethanol, based on known alcohol content of each beverage type and dose. For heavy drinkers who reported using over $600 \mathrm{gm}$ of ethanol weekly, the questionnaires and the corresponding codings were individually checked. Consequently, one subject was excluded from the study, because the reported alcohol use was based on a short period of binging. For stratified analyses, we divided the study sample into low-to-moderate and heavier drinkers by using the $75 \mathrm{th}$ percentile of the weekly consumption $(106 \mathrm{gm})$ as the cutpoint. Frequency of hangovers was assessed using a structured question ("How often did you experience hangover during the past 12 months?") with the following response alternatives: never, once a year, 2-3 times a year, 4-5 times a year, about once every 2 months, about monthly, 2-3 times a month, about once a week, at least twice a week. For the present analyses, we dichotomized the hangover variable (at least monthly ws less than monthly).

\section{Other Measurements}

The examination protocol and biochemical assessments in the KIHD study have been described in detail previously. ${ }^{24,27-29}$ Resting blood pressure was measured by one nurse with a random-zero muddler mercury sphygmomanometer. Resting heart rate was determined from the electrocardiogram, recorded in a supine position after 5 minutes of rest. History of cardiovascular diseases (angina pectoris, myocardial infarction, other ischemic heart disease, cardiac insufficiency, claudication, cerebrovascular diseases) was recorded with a self-administered questionnaire, which was checked by an interviewer and the examining physician. The lifelong exposure to smoking ("cigarette-years") was estimated as the product of years smoked and the number of cigarettes or equivalent tobacco products smoked daily at the time of examination. Current income was used to indicate socioeconomic status. Leisure-time physical activity was assessed from a 12-month history modified from the Minnesota Leisure Time Physical Activity Questionnaire; the intensity of physical activity was expressed in metabolic units (METs). ${ }^{30}$ Body mass index was calculated as weight $(\mathrm{kg})$ per height squared $\left(\mathrm{m}^{2}\right)$.

Data on systolic blood pressure were missing for 10 men, on body mass index for 7 men, on income for 31 men, on high-density lipoproteins (HDL) for 40 men, on low-density lipoproteins (LDL) for 51 men, on leisuretime physical activity for 19 men, and on plasma fibrinogen for 65 men; for these men, the mean value in the cohort was used.

\section{OUTCOME}

Cardiovascular mortality was ascertained by linkage to the national death registry. International Classification of Diseases, 9th revision, codes $390-459$ were used to define the cases of cardiovascular death. We included all cardiovascular deaths that occurred in the study sample between entry into the study and December 31, 1993 $(\mathrm{N}=58)$. The longest follow-up period was 9.8 years, and the mean follow-up time was 6.7 years.

\section{Statistical Analysis}

We assessed the association between frequent hangovers and risk of cardiovascular death using the Cox proportional hazards model. ${ }^{31}$ We performed the survival analyses separately for the total sample and for the two subgroups (low- and high-drinking group). We fit an age-adjusted model for the relation between the dichotomous hangover variable and the outcome and then examined changes in the relative hazard estimate by adding the total alcohol consumption variable in the model. We also checked the change in the estimates and the fitness of the model by using quadratic modeling of total alcohol use. We checked possible sources of confounding for a number of covariates: cigarette-years, income, prior cardiovascular diseases, leisure-time physical activity, and body mass index. We also carried out exploratory analyses of hypothesized mechanisms by sequentially adding systolic blood pressure, low- and highdensity serum lipoproteins, resting heart rate, and plasma fibrinogen concentration in the model.

\section{Results}

The mean weekly consumption of ethanol was $86.1 \mathrm{gm}$ (SD 131.5). The mean consumption level in the three lowest quartiles $(\mathrm{N}=1,633)$ was $33.9 \mathrm{gm}$ per week [standard deviation $(S D)=29.6$; range $=0.12-106.3$ gm per week], and in the fourth quartile $(\mathrm{N}=527)$, $247.8 \mathrm{gm}$ per week $(\mathrm{SD}=183.2 ;$ range $=107.0-2,284)$ (Table 1).

A total of 339 men (15.7\%) reported having a hangover at least monthly. Among heavier drinkers (fourth quartile), $43.8 \%(\mathrm{~N}=231)$ experienced hangover monthly or more often. In the three lowest quartiles, at least monthly hangover frequency was reported by only $6.6 \%$ of men $(\mathrm{N}=108$ ) (Table 1 ). The hangover variable, recoded as times per year and normalized by 
TABLE 1. Mean Age, Average Weekly Alcohol Use, and Hangover Frequency by the Level of Alcohol Consumption in Middle-Aged Finnish Men

\begin{tabular}{lccc}
\hline \hline & Total Sample & $\begin{array}{c}\text { Consumption } \\
\text { Quartiles 1-3 }\end{array}$ & $\begin{array}{c}\text { Consurmption } \\
\text { Quartile 4 }\end{array}$ \\
\hline Number of men & 2,160 & 1,633 & 527 \\
Mean age (SD) & $52.4(5.3)$ & $52.6(5.2)$ & $51.7(5.7)$ \\
Average weekly alcohol use (gm) & $86.1(131.5)$ & $33.9(29.6)$ & $247.8(183.2)$ \\
Hangover monthly or more often (\%) & $339(15.7)$ & $108(6.6)$ & $231(43.8)$ \\
\hline
\end{tabular}

Table 3 shows the distribution of cardiovascular risk factors and other relevant covariates in the total sample and in the fourth consumption quartile, by hangover frequency.

The age-adjusted relative risk of cardiovascular death associated with high hangover frequency was 2.26 [95\% con- logarithmic transformation, had a fairly high correlation with total alcohol use in the three lowest consumption quartiles $(r=0.47)$ but correlated weakly with total alcohol use in the highest quartile $(r=0.15)$.

Overall, there were 58 cardiovascular deaths during the follow-up. Of these, $48(83 \%)$ were diagnosed as ischemic heart disease, $8(14 \%)$ as cerebrovascular, and $2(3 \%)$ as other cardiovascular causes. Table 2 shows the number of cardiovascular deaths, the person-years of follow-up, and the cardiovascular mortality rate in the total sample and in the low- and high-drinking subgroups, by frequency of hangover.

The hangover frequency and the mortality rate were low in the three lowest drinking quartiles; we observed only one-cardiovascular-death-in-the subgroup that-combines low total alcohol consumption and frequent hangovers. We restricted further analyses to the toral sample and the heavier drinking group. fidence interval $(\mathrm{CI})=1.27-4.04]$ in the total study population and $2.40(95 \% \mathrm{CI}=1.05-5.52)$ in the fourth quartile. After adjusting for total average alcohol use, we observed a decreased relative risk for the total population $(\mathrm{RR}=1.90 ; 95 \% \mathrm{CI}=1.02-3.56)$, but in the fourth quartile, the adjustment had no appreciable effect on the estimates ( $R R=2.36 ; 95 \% \mathrm{CI}=1.02-5.48$ ) (Table 4). Adding a quadratic term for alcohol consumption also changed the magnitude of the estimated relative risk in the total population $(R R=1.60 ; 95 \%$ $\mathrm{CI}=0.82-3.11$ ) but had no appreciable effect in the fourth quartile ( $R R=2.31 ; 95 \% \mathrm{CI}=0.99-5.4)$, implying that the alcohol consumption effect on mortality is approximately log-linear in the latter group (Table 4). -Adjustment for cigarette-years reduced the estimated relative excess risk (percentage change in relative risk over 1.0 ) by $10.3 \%$. Adding income to the model further decreased the estimate by $15.6 \%$; prior cardiovascular

TABLE 2. Cardiovascular Deaths and Mortality Rates by Level of Alcohol Consumption and Hangover Frequency (High Hangover Frequency $=$ Once a Month or More Often)

\begin{tabular}{|c|c|c|c|c|c|c|}
\hline & \multicolumn{6}{|c|}{ Hangover Frequency } \\
\hline & \multicolumn{2}{|c|}{$\begin{array}{l}\text { Toral Sample } \\
(\mathrm{N}=2,160)\end{array}$} & \multicolumn{2}{|c|}{$\begin{array}{l}\text { Consumprion Quartiles } 1-3 \\
(\mathrm{~N}=1,633)\end{array}$} & \multicolumn{2}{|c|}{$\begin{array}{c}\text { Consumption Quartile } 4 \\
(\mathrm{~N}=527)\end{array}$} \\
\hline & $\begin{array}{c}\text { High } \\
(\mathrm{N} \stackrel{=339)}{=}\end{array}$ & $\begin{array}{c}\text { Low } \\
-(\mathbb{t}=1,821)\end{array}$ & $\begin{array}{c}\text { High } \\
(\mathrm{N}=108)\end{array}$ & $(\mathrm{N}=1,525)$ & $\stackrel{\text { High }}{(\mathrm{N}=231)}$ & $(N=296)$ \\
\hline $\begin{array}{l}\text { Cardiovascular deaths } \\
\text { Person-years of follow-up } \\
\text { Cardiovascular morrality } / 100,000 \\
\text { person-years }\end{array}$ & $\begin{array}{r}16 \\
2,280 \\
702\end{array}$ & $\begin{array}{r}42 \\
12,172 \\
345\end{array}$ & $\begin{array}{r}1 \\
801 \\
125\end{array}$ & $\begin{array}{r}33 \\
10,249 \\
322\end{array}$ & $\begin{array}{r}15 \\
1,474 \\
1,018\end{array}$ & $\begin{array}{r}9 \\
1,923 \\
468\end{array}$ \\
\hline
\end{tabular}

TABLE 3. Prevalence of Prior Cardiovascular Diseases,* Means, and Standard Deviations of Risk Factors and Other Relevant Covariates in the Total Sample $(\mathrm{N}=2,160)$ and in the Fourth Consumption Quartile $(\mathrm{N}=527)$, by Hangover Frequency

\begin{tabular}{|c|c|c|c|c|}
\hline & \multicolumn{4}{|c|}{ Hangover Frequency } \\
\hline & \multicolumn{2}{|c|}{ All Drinkers } & \multicolumn{2}{|c|}{ Heaviest Drinking Quartile } \\
\hline & High & Low & High & Low \\
\hline $\begin{array}{l}\text { Diagnosed cardiovascular condition* ar baseline (\%) } \\
\text { Mean weekly alcohol use (gm of ethanol) (SD) } \\
\text { Lifetime smoking (cigarette-years) (SD) } \\
\text { Mean taxable income/year (Finnish marks) (SD) } \\
\text { Systolic blood pressure (mmHg) (SD) } \\
\text { Serum LDL-cholesterol (mmol/liter) (SD) } \\
\text { Serum HDL-cholesterol (mmol/liter) (SD) } \\
\text { Body mass index (kg/m²) (SD) } \\
\text { Leisure-time physical activiry (METs) (SD) } \\
\text { Plasma fibrinogen (gm/liter) (SD) } \\
\text { Resting heart rare (beats/min) (SD) }\end{array}$ & $\begin{array}{l}136(40.1) \\
209.1(195.7) \\
332.0(421.6) \\
69,925(46.081) \\
134.9(18.4) \\
4.02(1.03) \\
1.32(0.33) \\
27.4(3.8) \\
107.6(138.7) \\
3.16(0.57) \\
62.9(11.4)\end{array}$ & $\begin{array}{c}661(36.3) \\
63.3(100.2) \\
144.0(300.8) \\
83,049(54.017) \\
133.7(16.3) \\
4.05(1.00) \\
1.29(0.30) \\
26.7(3.5) \\
113.6(136.8) \\
2.99(0.54) \\
62.2(10.7)\end{array}$ & $\begin{array}{l}88(38.3) \\
277.4(204.1) \\
332.5(436.9) \\
72,380(45,948) \\
135.8(18.6) \\
3.96(0.99) \\
1.34(0.33) \\
27.7(4.0) \\
116.8(154.1) \\
3.13(0.59) \\
63.3(11.7)\end{array}$ & $\begin{array}{c}108(36.4) \\
225.0(161.9) \\
258.9(420.2) \\
86,032(56,240) \\
136.7(16.9) \\
4.06(1.00) \\
1.33(0.35) \\
27.7(3.74) \\
99.8(127.8) \\
3.07(0.53) \\
64.4(11.6)\end{array}$ \\
\hline
\end{tabular}

* Angina pectoris, myocardial infarction, other ischemic hear disease, cardiac insufficiency, claudication, or cerebrovascular disease. 
TABLE 4. The Association of Frequent Hangovers with Cardiovascular Death in a Population Sample of Middle-Aged Finnish Men $(\mathrm{N}=2,160)$ and among Those $25 \%$ $(N=527)$ Who Have the Highest Average Alcohol Consumption, Adjusting for Age and Age + Total Alcohol Use

\begin{tabular}{|c|c|c|c|c|}
\hline \multirow[b]{2}{*}{ Adjusted for: } & \multicolumn{2}{|c|}{ Total Sample } & \multicolumn{2}{|c|}{$\begin{array}{c}\text { Highest Consumption } \\
\text { Quartile }\end{array}$} \\
\hline & $\begin{array}{l}\text { Relative } \\
\text { Risk }\end{array}$ & $\begin{array}{c}95 \% \\
\text { Confidence } \\
\text { Interval }\end{array}$ & $\begin{array}{l}\text { Relative } \\
\text { Risk }\end{array}$ & $\begin{array}{c}95 \% \\
\text { Confidence } \\
\text { Interval }\end{array}$ \\
\hline $\begin{array}{l}\text { Age } \\
\text { Age + total alcohol use } \\
\text { (linear model) }\end{array}$ & $\begin{array}{l}2.26 \\
1.90\end{array}$ & $\begin{array}{l}1.27-4.04 \\
1.02-3.56\end{array}$ & $\begin{array}{l}2.40 \\
2.36\end{array}$ & $\begin{array}{l}1.05-5.52 \\
1.02-5.48\end{array}$ \\
\hline $\begin{array}{l}\text { Age }+ \text { total alcohol use } \\
\text { (quadratic model) }\end{array}$ & 1.60 & $0.82-3.11$ & 2.31 & $0.99-5.41$ \\
\hline
\end{tabular}

effects of heavy acute drinking episodes. Hangover frequency measures acute exposures to several physiologic and metabolic changes in the body. Alcohol and its metabolites have a direct effect on the excitability and contractility of heart muscle, and with intoxicating doses there is a rise in cardiac rate and output as well as systolic and pulse pressures. These effects may constitute a pathway to ischemic, hemorrhagic, or arrhythmogenic processes during or after intoxication. ${ }^{39}$

diseases reduced the estimate by $11.7 \%$. Adding other covariates one at a time to the model had no appreciable effect, except for plasma fibrinogen, which changed the estimated relative risk downward by $11.5 \%$ (Table 5). In the full model with the joint control for all confounders, only cigarette-years, prior diseases, and plasma fibrinogen remained important predictors of cardiovascular death. The adjusted relative risk for frequent hangovers in the full model was 1.77 (95\% CI $=0.73-4.26)$.

\section{Discussion}

Drinking patterns have been studied surprisingly little in population studies. Yet, the usual drinking style can vary remarkably within the same average level of alcohol consumption and may have health effects independent of the total amount of alcohol use.

Although there are few epidemiologic studies on hangover, some related studies support our findings. A case-control study ${ }^{10}$ showed lower risk of ischemic stroke in light-to-moderate drinkers who had a regular consumption pattern, whereas a sporadic drinking patrern seemed to attenuate the possible beneficial effect.

The biological mechanisms by which alcohol use affects the development of cardiovascular diseases are

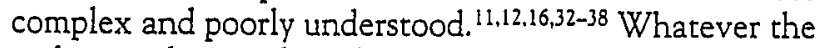
pathways that mediate long-term effects of heavy consumption, they most likely differ at least partly from the

TABLE 5. Change in the Age- and Total Alcohol Use-Adjusted Relative Excess Risk (Hangover at Least Monthly vs Others) in the Highest Consumption Quartile, after Adjustments for Potential Confounders and Other Covariates in the Nonquadratic Model; the Previous Covariates Remain in the Model as the New One Is Added

\begin{tabular}{lccc}
\hline \hline \multicolumn{1}{c}{ Added Covariace } & $\begin{array}{c}\text { Relative } \\
\text { Risk }\end{array}$ & $\begin{array}{c}95 \% \\
\text { Confidence } \\
\text { Interval }\end{array}$ & $\begin{array}{c}\text { Percentage Change in Relative } \\
\text { Excess Risk (RR - 1) from the } \\
\text { Previous Model }\end{array}$ \\
\hline Smoking & 2.22 & $0.95-5.22$ & -10.3 \\
Income & 2.02 & $0.85-4.78$ & -15.6 \\
Prior cardiovascular diseases & 1.91 & $0.81-4.52$ & -11.7 \\
Physical activity & 1.87 & $0.79-4.42$ & -4.4 \\
Systolic blood pressure & 1.82 & $0.76-4.35$ & -5.7 \\
Serum LDL-and HDL- & 1.88 & $0.78-4.53$ & +7.3 \\
$\quad$ cholesterol & & & -2.3 \\
Body mass index & 1.86 & $0.77-4.49$ & +1.2 \\
Resting heart rate & 1.87 & $0.77-4.51$ & -11.5 \\
Plasma fibrinogen & 1.77 & $0.73-4.25$ & \\
\hline
\end{tabular}

There is some evidence that hangovers associate with certain personality traits or states, such as neuroticism, hostility, and depressiveness. ${ }^{40}$ Thus, hangover effects might constitute one possible pathway for increased mortality observed with some of these factors.

Although this study was not designed to investigate causal mechanisms berween hangovers and cardiovascular mortality, we examined potentially mediating factors. Theoretically, elevated blood pressure among episodic heavy drinkers could partly account for the observed mortality differences, ${ }^{11,12}$ but adjustment for systolic blood pressure in this study had virtually no effect on the relative risk. Increased heart rate at rest reflects heightened sympathetic tone of the autonomic nervous system and may increase the risk of cardiac arrhythmia and subsequent ischemia. In our analyses, however, heart rate had no effect on the findings. Similarly, controlling for serum lipids and body mass index changed the estimates very litrle. We found a larger reduction in the excess risk due to hangovers after adjustment for plasma fibrinogen concentration. Epidemiologic studies ${ }^{41-43}$ indicate a strong association between plasma fibrinogen, an acute phase protein involved in the clotting process, and cardiovascular diseases. The harmful effects of excessive and episodic heavy drinking resulting in intoxication and hangover may be mediated in part by this acute phase protein.

Factors such as tolerance of alcohol due to prolonged heavy consumption may cause differences in the way that individuals are affected by excessive drinking. Assuming that heavy drinkers suffer from hangovers less often than moderate drinkers in relation to their total consumption level, the observed relation would be biased toward the null. Population studies are likely to underestimate the total consumption of alcohol in any given study group. ${ }^{8}$ This error may also bias the findings toward the null, 
given that there is no differential misclassification across various consumption levels. ${ }^{44}$ We have no reason to assume, for example, that there is more underreporting of hangovers at lower levels of alcohol consumption.

Heavy drinking remains one of the leading avoidable causes of death. The current results indicate that preventive actions should focus not only on total consumption, but also on the way people drink.

\section{Acknowledgments}

We thank Kimmo Ronkainen for his assistance in daca analyses, and Kari Poikolainen for providing the Nordic Alcohol Consumprion Inventory for us.

\section{References}

1. Shaper AG, Wannamechee G, Walker M. Alcohol and coronary heart disease: a perspective from the British Regional Hearr Srudy. In J Epidemiol 1994:23:482-492.

2. Coare D. Moderace drinking and coronary heart disease mortaliry: evidence from NHANES I and the NHANES II follow-up. Am J Public Health 1993:83:888-890.

3. Beaglehole R, Jackson R. Alcohol, cardiovascular diseases and all causes of mortality: a review of the epidemiological evidence. Drug Alcohol Rev $1992 ; 2: 275-290$.

4. Klatsky AL, Amstrong MA. Alcoholic beverage choice and coronany artery disease: do red wine drinkers fare best? Circulation 1992;86(supp l) :T:342348.

5. Marmor $M$, Brunner E. Alcohol and cardiovascular disease: the starus of the U-shaped curve. BMj 1991;303:565-568.

6. Klatsky AL, Armstrong MA. Friedman GD. Risk of cardiovascular murcality in alcohol drinkers, ex-drinkers and nondrinkers. Am J Cardiol 1990;66: 1237-1242.

7. Dyer AR, Stamler J, Oglesby P, Lepper M, Shekelle RB, McKean H, Garside D. Alcohol consumprion and 17-year mortality in the Chicago Western Electric Company Study. Prev Med 1980;9:78-90.

8. Poikolainen K. Alcohol and mortality: a review. J Clin Epiderniol 1995;48: $455-465$.

9. Gruchow HW, Hoffman RG, Anderson A], Barboriak J]. Effects of drinking parterns on the relationship berween alcohol and coronary occlusion. Atherosclerosis 1982;43:393-404.

10. Palomäki H. Kaste M. Regular light-to-moderate incake of alcohol and the risk of ischemic stroke. Is there a beneficial effect? Stroke 1993;24:18281832 .

11. Marmot MG, Elliott P, Shipley MJ, Dyer AR, Ueshima H,-BeEvers DG, Stamler R, Kesteloor H, Rose G, Stamler J. Alcohol and blood pressure: the INTERSALT study. BMJ 1994;308:1263-1267.

12. Seppä K, Laippala P, Sillanaukee P. Drinking partern and bloot pressure. Am J Hypertens 1994;7:249-254.

13. Klatsky AL, Friedman GD, Armstrong MA. Relationships between alco. holic beverage use and orher trairs ro blood pressure: a new Kaiser Permainente Study. Circulacion 1986;73:628-636.

14. Stampfer MíJ, Colditz GA, Willert WC, Speizer FE, Hennekens CH. A prospective study of moderate alcohol consumption and the risk of coronary disease and stroke in women. N Engl J Med 1988;319:267-273.

15. Cohen EJ, Klatsky AL, Amstrong MA. Alcohol use and supraventricular arthythmia. Am J Cardiol 1988;62:971-973.

16. Regan T]. Alcoholic cardiomyopachy. Prog Cardiovase Dis 1984;27:141152

17. Friedman LA, Kimball AW. Coronary heart disease mortaliry and alcohol consumprion in Framingham. Am ] Epidemiol 1986;124:481-489.

18. Rimm EB, Giovannucci EL. Willert WC, Colditz GA, Ascherio A, Rosner B, Srampfer MJ. Prospective study of alcohol consumption and risk of coronary disease in men. Lancet 1991;338:464-468.

19. Klassky AL. Alcohol and coronary artery disease. Alcohol Health Wurld $1990 ; 14: 289-300$.

20. Perersson B. Analysis of the role of alcohol in morcality, parricularly sudden unwitnessed deach in middle-aged men in Malmö, Sweden. Alcohol Alcohol $1988 ; 23: 259-263$.

21. Perola $M$, Vuori E, Pentrilia A. Abuse of alcohol in sudden out-of-hospital deachs in Finland. Alcohol Clin Exp Res 1994;18:255-260.

22. Alcohol Statistical Yearbook 1994. Helsinki: Oy ALKO Ab, Finnish State Alcohol Co., 1995.

23. Simpura J, ed. Finnish Drinking Habits: Results from Interview Surveys Held in 1968, 1976, 1984. vol. 35. Helsinki: Finnish Foundation for Alcohol Sudies, 1987.

24. Salonen JT. Is there a continuing need for longitudinal epidemiological research? The Kuopio Ischaemic Hearc Disease Risk Factor Srudy. Ann Clin Res 1988;20:46-50.

25. Hauge R, Irgens-Jensen O. Scandinavian Dinking Survey: Sampling Operations and Daca Collections. SIFA-stensilserie 44. Oslo: National Institute for Alcohol Research (SiFA), 1981.

26. Kauhanen J, Julkunen J, Salonen JT. Coping with inner feelings and stress: heavy alcohol use in the contexr of alexithymia. Behav Med 1992;18:121126.

27. Salonen JT, Nyyssönen K, Korpela H, Tuomilehro J, Seppänen R, Salonen R. High stored iron levels are associated with excess risk of myocardial infarction in Eastem Finnish men. Circulation 1992;86:803-811.

28. Salonen JT, Salonen R, Seppänen K, Rauramaa R, Tuomilehto J. HDL, $\mathrm{HDL}_{2}$, and $\mathrm{HDL}_{3}$ subfractions, and the risk of acute myocardial infarction: a prospecrive population study in Eastern Finnish men. Circulation 1991;84: $129-139$.

29. Wilson TW, Kapian GA, Kauhanen J. Cohen RD, Wu M. Salonen R, Salonen JT. Association becween plasma fibrinogen concentration and five socioeconomic indices in the Kuopio Ischemic Hear Disease Risk Factor Study. Am J Epidemiol 1993;137:202-300.

30. Lakka TA. Veräläinen JM, Rauramaa R, Salonen $R$, Tuomilehto J, Salonen JT. Relarion of leisure-time physical activity and cardiorespiratory fitness to the risk of acuce_myocardial infarction in men. N Engl J Med 1994:330. $1549-1554$.

31. Cox DR. Onkes D. Analysis of Survival Data. New York: Chapman \& Hall, 1984.

32. Gariano JM, Buring JE. Breslow JL, Goluhater SZ. Rusner B, VanDenburgh M. Willect W. Hennekens CH. Moderate alcohol intake. increased levels of high-density lipoprorein and its subfractions, and decreased risk of myocardial infarctiun. N Engl J Med 1993:329:19?9-1834.

33. Fruser GE, Andersun JT, Foster N, Culuberg R. Jacobs D, Blackbum H. The effect of alcohol on senum high densing lipoputein (HDL): a concrolled experiment. Atherosclerosis 1983:46:275-286.

34. Hulley SE. Gordon S. A.cohol and high-density lipoprocein cholesterol: causal interence from diverse study designs. Circulation 1981:64(suppl 3): $57-63$.

35. Huang C-M, Elin RJ, Ruddle M, Schmitz J, Linnoila $M$. The effect of alcuhol withdrawal on serum concentrarions of $L P(a)$, apolipoproteins $A-1$, and $B$, and lipids. Alcohol Clin Exp Res 1992:16:895-898.

36. Renaud S. De Lurgeril M. Wine, alcohol, flatelers, and the French paradox for coronary heart disease. Lancer 1992;339:1523-1526.

37. Mikhailidis DF. Jetemy JY, Barradas MA, Green N, Dandona P. Effect of ethanol un vascular prostacyclin synthesis, platelet aggregation, and plateles chromboxane release. Br Med ] Clin Res Ed 1983;287:1495-1498.

38. Razay G, Heiton KW, Bolton $\mathrm{CH}$, Hughes $A \mathrm{O}$. Alcohol consumprion and its relation to cardiovascular risk factors in British women. BMJ 1992;304: $80-83$.

39. Ylikahri R. Huttunen MO. Eriksson P, Nikkila EA. Metabolic studies on the parhogenesis of hangover. Eur J Clin Invest 1974;4:93-100.

40. Harburg E, Gunn R, Gleiberman L. DiFranceisco W, Schork A. Psychusocial factors, alcohol use, and hangover signs among social drinkers: a reapproisal. J Clin Epidemiol 1993:46:413-422.

41. Meade TW. Chakrabarti R, Haines AP, North WRS, Stirling Y. Characceristics affecting fibrinolytic activity and plasma fibrinogen concentrations. BMJ 1979;1:153-156.

42. Wilhelmsen L, Svardsudd K, Korsan-Bengesen. K, Larsson B, Welin L, Tibblin G. Fibrinugen as a risk factor for stroke and myocardial infarction $N$ Engl J Med 1984;311:501-505.

43. Kannel WB, D'Agostino RB, Wilson PW, Belinger AJ, Gagnon DR. Diisbetes, fibrinogen, and risk of cardiovascular disease: the Framinghum experience. Am Heart I 1990;120:672-676.

44. Fleiss JL. Statistical Merhods for Rates and Propurtions. 2nd ed. New York: John Wiley and Suns, 1981. 




